\title{
Video Article \\ Efficient Production and Purification of Recombinant Murine Kindlin-3 from Insect Cells for Biophysical Studies
}

\author{
Luke A. Yates ${ }^{1}$, Robert J. C. Gilbert ${ }^{1}$ \\ ${ }^{1}$ Division of Structural Biology, Wellcome Trust Centre for Human Genetics, University of Oxford \\ Correspondence to: Luke A. Yates at luke@strubi.ox.ac.uk, Robert J. C. Gilbert at gilbert@strubi.ox.ac.uk
}

URL: https://www.jove.com/video/51206

DOI: doi: $10.3791 / 51206$

Keywords: Virology, Issue 85, Heterologous protein expression, insect cells, Spodoptera frugiperda, baculovirus, protein purification, kindlin, cell adhesion

Date Published: 3/19/2014

Citation: Yates, L.A., Gilbert, R.J. Efficient Production and Purification of Recombinant Murine Kindlin-3 from Insect Cells for Biophysical Studies. J. Vis. Exp. (85), e51206, doi:10.3791/51206 (2014).

\section{Abstract}

Kindlins are essential coactivators, with talin, of the cell surface receptors integrins and also participate in integrin outside-in signalling, and the control of gene transcription in the cell nucleus. The kindlins are $\sim 75 \mathrm{kDa}$ multidomain proteins and bind to an NPxY motif and upstream T/S cluster of the integrin $\beta$-subunit cytoplasmic tail. The hematopoietically-important kindlin isoform, kindlin-3, is critical for platelet aggregation during thrombus formation, leukocyte rolling in response to infection and inflammation and osteoclast podocyte formation in bone resorption. Kindlin-3's role in these processes has resulted in extensive cellular and physiological studies. However, there is a need for an efficient method of acquiring high quality milligram quantities of the protein for further studies. We have developed a protocol, here described, for the efficient expression and purification of recombinant murine kindlin-3 by use of a baculovirus-driven expression system in Sf9 cells yielding sufficient amounts of high purity full-length protein to allow its biophysical characterization. The same approach could be taken in the study of the other mammalian kindlin isoforms.

\section{Video Link}

The video component of this article can be found at https://www.jove.com/video/51206/

\section{Introduction}

Proteins of the kindlin family are a crucial component of focal adhesion assembly, and therefore essential for complex life. Kindlins, of which there are 3 isoforms in mammals (kindlin-1, kindlin-2, and kindlin-3), are considered coactivators of the extracellular receptors integrins alongside talin $^{1}$. Integrin-mediated cell adhesion connects the cell surface to the extracellular matrix (ECM) in higher eukaryotes. It is a critical and common process in a plethora of physiological phenomena, which include tissue integrity, embryogenesis, bone metabolism, hemostasis, and immunity. Integrin-mediated cell adhesion is activated through inside-out signal transduction via the binding of talin and kindlin to the integrin $\beta$-subunit cytoplasmic tails (CTs) at their conserved NPxY motifs. The biomedical importance of kindlin proteins extends however as far as the nucleus, where kindlin-2 has been shown in several recent reports to be involved in transcriptional control ${ }^{2,3}$.

Kindlins are multidomain proteins of approximately $75 \mathrm{kDa}$, hallmarked by the possession of a bipartite C-terminal FERM (4.1 band, ezrin, radixin, moesin) domain, which is interrupted by a pleckstrin homology $(\mathrm{PH})$ domain at the center of its $\mathrm{F} 2$ subdomain ${ }^{4,5}$. Studies of the kindlin-2 and kindlin-3 PH domains showed that it binds to the lipid second messengers phosphatidylinositol-(3,4,5)-trisphosphate and phosphatidylinositol-(4,5)-bisphosphate ${ }^{6-8}$. However, studies of the kindlin-1 PH domain show that it binds to $\mathrm{Ptdlns}(3,4,5) \mathrm{P}_{3}$ with a much lower affinity, which can be explained in kindlin- 1 by an isoform-specific salt bridge preventing lipids from binding ${ }^{9}$. In addition, there is an $\sim 100$ amino acid loop inserted into the F1 domain of the kindlins that is predicted to be unfolded but binds to phosphatidylserine in the inner leaflet of the plasma membrane ${ }^{10,11}$. The kindlin FERM domain is considered homologous to the talin FERM domain, although the talin FERM domain does not possess a pleckstrin homology domain. Both kindlins and talin interact with NPxY motifs on the integrin $\beta$-tails via the F3 region of their FERM domain, but kindlin binds to the membrane distal motif, while talin targets the membrane proximal one ${ }^{12-16}$. Kindlins and talin both in addition possess an N-terminal F0 domain with a ubiquitin-like fold that is not found in other FERM proteins ${ }^{11,17}$. Studies on the F0 domain of kindlin-2 have shown that it independently binds to phosphatidylinositol-(4,5)-bisphosphate enriched membranes ${ }^{17}$.

The kindlins exhibit paralogue-specific tissue expression patterns and nonredundant physiological functions. Kindlin-1 is primarily expressed in the epidermis, but also to a lesser extent the colon, stomach, and kidneys; kindlin-2 is ubiquitously expressed but is concentrated in striated and smooth muscle and is the only kindlin expressed in embryonic development ${ }^{4}$; and kindlin- 3 is expressed in the hematopoietic tissues with the highest concentration of kindlin-3 found in megakaryocytes ${ }^{18}$. However, more recent studies have suggested that functional protein is expressed in endothelial tissues as well ${ }^{19}$.

Kindlin-3 is of acute medical interest due to its important physiological role in the blood. It is critical for platelet aggregation and spreading during thrombus formation ${ }^{20}$, leukocyte rolling in response to infection and inflammation ${ }^{21,22}$ and osteoclast podocyte formation in bone resorption ${ }^{23}$. Furthermore, depletion of kindlin-3 in humans leads to leukocyte adhesion deficiency type-III - a disease characterized by life-threatening 
bleeding disorders and recurrent bacterial infections ${ }^{20,24,25}$. Kindlin-3 knock-out studies in mice revealed the crucial function of the protein in cell adhesion. $\mathrm{KIND}^{-/-}$mice display distinct phenotypes, such as severe bleeding due to inactive platelet integrins, severe osteopetrosis, and impaired leukocyte adhesion ${ }^{20,22}$, resembling symptoms in humans lacking kindlin-3.

High-resolution structural data on the kindlins, to date, has been restricted to individual subdomains such as the pleckstrin homology $(\mathrm{PH})$ domain of kindlin- $1^{9}$ and kindlin- $2^{26,27}$ and the F0 domain of kindlin- $1^{11}$ and kindlin- $2^{17}$. Most of the subdomains of each kindlin polypeptide have however resisted cloning and structural analysis (Yates and Gilbert, unpublished observations), and studies of the full-length proteins have been hindered by the difficulty of expressing and purifying sufficient quantities using $E$. coli (unpublished observations and Harburger et $\left.a_{l}{ }^{14}\right)$. There is considerable medical interest in kindlin-3 and its function, alongside the other two family members, and recently we generated milligram quantities of it by recombinant expression in Spodoptera frugiperda cells driven by baculovirus infection ${ }^{12}$. We therefore here describe methods for the production of milligram quantities of recombinant mouse kindlin-3 in insect cell culture, suitable for extensive structural studies and biochemical analysis.

In this protocol we make use of an engineered knockout bacmid (BAC10 $\left.\mathrm{KO}_{1629}\right)$ that is, alone, unable to produce viable virions ${ }^{28}$. The viral DNA is thus rescued by recombination with a transfer vector that in this case also includes the kindlin-3 gene (FERMT3) and results in the FERMT3 gene replacing the virus very late gene, which is highly expressed but redundant, resulting in a recombinant virus that expresses mouse kindlin-3 as part of the virus life cycle ${ }^{28}$. We identified this method for the production of kindlin-3 after attempts to express and purify it in other expression hosts proved prohibitively difficult (unpublished observations) but also due to the versatility of the pOPIN vector suite, which we used for cloning and that can deployed in many expression hosts ${ }^{29}$.

\section{Protocol}

This protocol assumes that the mouse kindlin-3 gene (FERMT3) has been successfully cloned into a vector downstream of the very late $\mathrm{p} 10$ promoter and that the vector possesses flanking baculovirus sequences to permit recombination with the bacmid BAC $10_{K O} 1629$ developed by I.M Jones and colleagues ${ }^{28}$. For this protocol, the kindlin-3 gene was cloned into pOPINE ${ }^{29}$ and the primers and cloning strategy used can be found described elsewhere ${ }^{12}$. The plasmid is engineered so that the FERMT3 gene (kindlin-3) is under the control of the p10 baculoviral promoter and the vector contains 5' UTR/ORF603 and ORF 1629 and encodes a C-terminal His ${ }_{6}$-tag for downstream purification ${ }^{29}$.

\section{Insect Cell Culture and Maintenance}

1. Prior to recombinant baculovirus amplification, Spodoptera frugiperda cells adapted to suspension culture (Sf9 cells) should be grown and maintained. Insect cells should always be handled using aseptic techniques in a dedicated tissue culture fume hood.

2. Suspension cultures of insect cells are incubated in Sf-900 II (SFM) serum free liquid medium supplemented with $100 \mu \mathrm{g} / \mathrm{ml}$ penicillin and 100 $\mu \mathrm{g} / \mathrm{ml}$ streptomycin in flasks at $27^{\circ} \mathrm{C}$ with shaking at $100 \mathrm{rpm}$.

3. Maintain the insect cell culture density range between $1 \times 10^{6}-1 \times 10^{7}$ cells/ml by splitting and diluting the cell culture with fresh Sf-900 II media.

Note: healthy cells should look uniform in size and should be spherical in shape.

4. Count the cells in a sample volume using a hemocytometer and light microscopy to calculate the culture cell density.

\section{Generation of Recombinant Baculovirus}

1. Culture and maintain Sf9 cells in suspension using Sf-900 II media supplemented with $100 \mu \mathrm{g} / \mathrm{ml}$ penicillin and $100 \mu \mathrm{g} / \mathrm{ml}$ streptomycin. For baculovirus generation, insect cells should be cultured to a density range of $5 \times 10^{5}-1 \times 10^{6} \mathrm{cells} / \mathrm{ml}$.

2. Seed approximately $1 \times 10^{6} \mathrm{Sf9}$ cells per well of a sterile 6-well tissue culture plate in $2 \mathrm{ml}$ of Sf-900 II media supplemented with $100 \mu \mathrm{g} / \mathrm{ml}$ penicillin and $100 \mu \mathrm{g} / \mathrm{ml}$ streptomycin. Leave the Sf9 cells at RT in the fume hood to adhere to the base of the plastic wells and thus form a monolayer.

3. Perform recombinant baculovirus generation by cotransfecting bacmid DNA and plasmid DNA onto monolayer culture.

1. For each transfection, mix 1-2 $\mu \mathrm{g}$ of purified pOPINE-mFERMT3, which possesses the ORF1629 baculovirus elements, with $0.5 \mu \mathrm{g}$ of purified BAC10 $1 \mathrm{KO}_{1629}$ in $100 \mu \mathrm{l}$ of Sf-900 II SFM without antibiotics (Solution A).

2. In a separate tube, dilute $6 \mu \mathrm{l}$ of Cellfectin II Reagent with $100 \mu \mathrm{l}$ of Sf-900 II SFM without antibiotics for each transfection reaction (Solution B). A 'master mix' can be created here, for reduced liquid handling, if many transfections are required.

3. Mix the two solutions ( $A$ and B, approximately $200 \mu \mathrm{l}$ ) and incubate at RT for 20 min to form a lipid-DNA complex.

4. Dilute the lipid-DNA complexes with $800 \mu \mathrm{l} \mathrm{Sf-900} \mathrm{II} \mathrm{SFM} \mathrm{without} \mathrm{antibiotics.} \mathrm{Carefully} \mathrm{aspirate} \mathrm{the} \mathrm{Sf9} \mathrm{cell} \mathrm{monolayer} \mathrm{media} \mathrm{and}$ carefully pipette the solution $\mathrm{A} / \mathrm{B}$ and media on top of the Sf9 monolayer.

5. Incubate the transfected cells in a humidified incubator at $27^{\circ} \mathrm{C} \mathrm{O} / \mathrm{N}$ and add a further $1 \mathrm{ml}$ of Sf-900 II SFM without antibiotics to each monolayer culture the following day. Incubate cells at $27^{\circ} \mathrm{C}$ for a further 5 days.

4. Harvest the recombinant baculovirus directly from the culture medium (approximately $2 \mathrm{ml}$ in total) and transfer to a clean centrifuge tube (for example a $15 \mathrm{ml}$ Falcon tube).

1. Clarify any Sf9 cell debris by centrifugation at $1,000 \times \mathrm{g}$ for $5 \mathrm{~min}$ at RT. Transfer the virus, which is in the resulting supernatant and denoted $\mathrm{P} 1$, to a clean tube and store at $4{ }^{\circ} \mathrm{C}$ in the dark until use. At this stage the remaining Sf9 monolayer can be used to assess recombinant virus generation by assessing the presence of recombinant kindlin- 3 in the insect cells.

5. Resuspend the monolayer with $0.5 \mathrm{ml}$ PBS and dilute a $10 \mu \mathrm{l}$ sample with equal volumes of $2 x$ SDS-PAGE loading buffer. Heat the samples at $>95^{\circ} \mathrm{C}$ for at least $10 \mathrm{~min}$.

1. Sonicate the sample for $1 \mathrm{sec}$ at $10 \%$ amplitude using a micro-sonicator tip if it is too viscous for proper gel loading. 


\section{Amplification of Recombinant Baculovirus}

1. For the amplification of virus in suspension, use a cell density of $1.4 \times 10^{6}$ cells $/ \mathrm{ml}$ and this should occupy $1 / 20$ of the total flask volume (i.e. $50 \mathrm{ml}$ culture in a $2 \mathrm{~L}$ flask).

2. Achieve the amplification of the recombinant virus by infecting the insect cell culture with the P1 viral stock at a multiplicity of infection (MOI) of 0.1 using the following formula;

inoculum required $(\mathrm{ml})=\frac{\text { desired } \mathrm{MOl}(\mathrm{pfu} / \mathrm{ml}) \times(\text { total number of cells })}{\text { titer of viral inoculum }(\mathrm{pfu} / \mathrm{ml})}$

Note: P1 virus generation can be assumed to have an expected viral titer of $1 \times 10^{7} \mathrm{pfu} / \mathrm{ml}$. However, a plaque assay can be performed prior to this stage.

3. Incubate the $\mathrm{P} 1$-infected insect culture at $27^{\circ} \mathrm{C}$ with shaking at $100 \mathrm{rpm}$ for 3 days $(72 \mathrm{hr})$.

4. Harvest the virus by separating the cells from the media by centrifugation at $1,000 \times \mathrm{g}$ for $5 \mathrm{~min}$ at RT. Save the resulting cell pellet at this stage for confirmation of recombinant virus production by assessing kindlin-3 protein expression by SDS-PAGE and western blotting.

5. Transfer the clarified virus-enriched media to a clean tube and store at $4{ }^{\circ} \mathrm{C}$ in the dark until use. This viral stock is denoted as $\mathrm{P} 2$. Note: A viral titer of $2 \times 10^{8} \mathrm{pfu} / \mathrm{ml}$ (or an amplification rate of $100 \mathrm{pfu} / \mathrm{cell}$ ) can be anticipated.

\section{Expression of kindlin-3 in Baculovirus-Infected Sf9}

1. Grow an adequate volume of Sf9 cells cultures in suspension in Sf-900 II SFM supplemented with $100 \mu \mathrm{g} / \mathrm{ml}$ penicillin and $100 \mu \mathrm{g} / \mathrm{ml}$ streptomycin, prior to large-scale recombinant kindlin-3 expression for purification. Incubate the suspension cultures at $27^{\circ} \mathrm{C}$ with shaking at $100 \mathrm{rpm}$ and with a total culture volume:flask volume ratio of 1:5.

2. Infect suspension cultures of Sf9 at a density of $2 \times 10^{6}$ cells $/ \mathrm{ml}$.

3. Supplement Sf9 cultures with a final concentration of $1 \%(\mathrm{v} / \mathrm{v})$ Fetal Bovine Serum (FBS) followed with amplified recombinant virus (P2-viral stock) to give a MOI of 1 . Incubate the infected cultures at $27^{\circ} \mathrm{C}$ with shaking at $100 \mathrm{rpm}$.

4. Harvest recombinant kindlin-3-CHIS -expressing Sf9 cells $72 \mathrm{hr}$ post-infection by centrifugation at $1,000 \times \mathrm{g}$ and the resulting cell pellet stored at $-20{ }^{\circ} \mathrm{C}$ until use, or $-80^{\circ} \mathrm{C}$ for long term storage.

\section{Purification of Recombinant Kindlin-3}

1. Thaw frozen baculovirus-infected insect cell (Sf9) pellets expressing recombinant kindlin-3 on ice.

2. Resuspend the thawed cell pellet with lysis buffer (50 mM Tris-HCl, pH 7.5, $500 \mathrm{mM} \mathrm{NaCl}, 1 \%$ (v/v) Tween-20), supplemented with EDTA-free protease inhibitor cocktail and 1,000-2,000 $\mathrm{U}$ of DNase1.

Note: Alternatively, modified phosphate buffered saline (PBS) can also be used, where the $\mathrm{NaCl}$ concentration is adjusted to $500 \mathrm{mM}$ to prevent nonspecific interactions between endogenous Sf9 cell proteins and the immobilized metal affinity column used for downstream purification (see below).

3. Lyse the cells by incubating the resuspended cells with the detergent and vortexing. Sonicate ( $40 \%$ amplitude, 10 cycles of 10 sec pulse followed by $10 \mathrm{sec}$ cooling) the sample for further cell disruption in an ice bath or alternatively use a Dounce homogenizer.

4. Clarify the lysate by centrifugation at $48,000 \times \mathrm{g}$ for $1 \mathrm{hr}$ at $4{ }^{\circ} \mathrm{C}$. Load the resulting supernatant onto a HisTrap column (5 $\mathrm{ml}$ column volume), pre-equilibrated with lysis buffer, at $4{ }^{\circ} \mathrm{C}$ at a rate of $1 \mathrm{ml} / \mathrm{min}$.

Note: Alternatively, the clarified lysate can be incubated with a 1-5 ml bed volume of pre-equilibrated nickel sepharose beads (e.g. $\mathrm{Ni}$ Sepharose 6 fast flow) at $4{ }^{\circ} \mathrm{C}$ for $1-2 \mathrm{hr}$. A column of Ni sepharose can be formed after the binding step by using a gravity flow column.

5. Wash the column with 10 column volumes of wash buffer $(50 \mathrm{mM}$ Tris- $\mathrm{HCl}, \mathrm{pH} 7.5,500 \mathrm{mM} \mathrm{NaCl}, 10 \mathrm{mM}$ imidazole) to remove unbound proteins.

6. Use a linear imidazole gradient from $10-500 \mathrm{mM}$ at a rate of $10 \mathrm{mM} / \mathrm{ml}$ (or in 10 column volumes) using an Äkta FPLC to elute the bound recombinant kindlin-3-CHIS

7. Fractionate the elution into $0.5-1 \mathrm{ml}$ fractions using the Äkta FPLC, with those fractions containing kindlin-3-CHIS 6 usually eluting at an imidazole concentration of $300 \mathrm{mM}$.

8. Assess the protein composition of the eluant by SDS-PAGE and for first-time purifications confirm by western blotting using an anti-His 6 antibody or anti-mouse kindlin-3 antibody.

9. Pool the fractions containing kindlin-3 and buffer exchange into $20 \mathrm{mM}$ Tris- $\mathrm{HCl}, \mathrm{pH} 7.5,200 \mathrm{mM} \mathrm{NaCl}$ via a series of dilutions into buffer and sample concentrations using a centrifugal protein concentrator with a $50 \mathrm{kDa}$ molecular weight cut-off (MWCO) at $4^{\circ} \mathrm{C}$.

Note: Alternatively, dialyze the protein solution using Slide-A-lyzer Dialysis Cassette with a MWCO of $30 \mathrm{kDa}$ at $4{ }^{\circ} \mathrm{C}$ for $4 \mathrm{hr}$ to $\mathrm{O} / \mathrm{N}$ into 20 $\mathrm{mM}$ Tris- $\mathrm{HCl}, \mathrm{pH} 7.5,200 \mathrm{mM} \mathrm{NaCl}$.

Note: for ion exchange (see below) a lower concentration of $\mathrm{NaCl}$, i.e. $50 \mathrm{mM}$, can be and has been used for this step.

10. Apply the buffer-exchanged protein solution onto a pre-equilibrated HiTrap heparin HP column ( $5 \mathrm{ml}$ column volume) using an Äkta FPLC at a rate of $0.5 \mathrm{ml} / \mathrm{min}$.

Note: The bound kindlin-3 is eluted using a linear $\mathrm{NaCl}$ gradient $(0.2 \mathrm{M} \mathrm{NaCl}$ to $1 \mathrm{M} \mathrm{NaCl})$ in the same buffer, increasing at a rate of $10 \mathrm{mM} /$ $\mathrm{ml}$. Kindlin-3-CHIS6 is expected to elute at $\sim 0.6 \mathrm{M} \mathrm{NaCl}$.

11. Fractionate the elution into $0.5-1 \mathrm{ml}$ fractions and assess the protein composition by SDS-PAGE and western blotting, if appropriate. Note: one can expect a protein purity of close to $95 \%$, as assessed by SDS-PAGE.

12. Pool fractions containing kindlin-3 and concentrate using a centrifuge protein concentrator with a $50 \mathrm{kDa}$ MWCO to a final volume of $0.5-2 \mathrm{ml}$.

13. In a final step, polish the concentrated protein and buffer exchange the protein using size exclusion chromatography (SEC).

1. Apply the purified protein onto a Superdex $\mathrm{S} 200$ (16/60) or (10/30) pre-equilibrated in $20 \mathrm{mM} \mathrm{Tris-HCl,} \mathrm{pH} \mathrm{7.5,} 200 \mathrm{mM} \mathrm{NaCl}, 1 \mathrm{mM}$ DTT at a rate of $1 \mathrm{ml} / \mathrm{min}$ or $0.5 \mathrm{ml} / \mathrm{min}$ depending on column size used.

Note: Size exclusion chromatography can also be performed in phosphate-buffered saline (PBS) if required.

2. Purify the proteins according to size by applying buffer onto the column at a rate of $1 \mathrm{ml} / \mathrm{min}$ or $0.5 \mathrm{ml} / \mathrm{min}$, depending on column size used. 
Note: The protein eluting from the column is fractionated and monitored using the absorbance at $280 \mathrm{~nm}$.

3. A single absorbance peak should be expected from SEC, which is fractionated and assessed by SDS-PAGE to determine homogeneity, and is typically $>95 \%$ pure after this step.

14. Concentrate the purified kindlin-3-CHIS ${ }_{6}$ using a centrifuge protein concentrator with a $50 \mathrm{kDa} \mathrm{MWCO}$ to $\sim 15 \mathrm{mg} / \mathrm{ml}$, as assessed spectrophotometrically using a calculated extinction coefficient $(\varepsilon)$ of $109,320 \mathrm{M}^{-1} \mathrm{~cm}^{-1}$ (assuming all cysteine residues are reduced).

15. For storage at $-20^{\circ} \mathrm{C}$ and long term storage at $-80^{\circ} \mathrm{C}$, aliquot the protein into PCR tubes and flash-freeze the samples in liquid nitrogen. Alternatively, the protein can be used directly for investigation using a number of biochemical and biophysical techniques.

\section{Representative Results}

The large scale expression of recombinant mouse kindlin-3 using baculovirus-infected Sf9 cells can take less than two weeks to achieve milligram quantities, as illustrated in the schematic Figure 1A and requires only a small quantity of plasmid DNA from a QIAprep Miniprep kit, for example. The generation of recombinant baculovirus is achieved by cotransfecting Sf9 cells with mouse kindlin-3 (FERMT3)-containing plasmid together with an engineered linearized bacmid $\left(\mathrm{BAC10}: \mathrm{KO}_{1629}\right)$ and harvesting the newly formed virions after 5-7 days, as shown in Figure $1 \mathrm{~A}$. This method of baculovirus generation results in $100 \%$ recombinant viruses and essentially dispenses the need for plaque purification ${ }^{28,30}$. A representative small-scale ( $2 \mathrm{ml}$ monolayer) culture will generate a recombinant virus-containing solution with an expected viral titer of $1 \times 10^{7}$ plaque forming units (pfu) per $\mathrm{ml}$ of culture. One can perform a plaque assay to determine the actual viral titer but this is perhaps too laborintensive when a high number of constructs are tested for structural studies. The success of the virus generation step can be assessed by using an eGFP-containing plasmid in parallel, or, for this kindlin-3 construct, the Sf9 monolayer can be resuspended in PBS and assessed by SDSPAGE and western blotting, which typically demonstrates a clear band corresponding to a $75 \mathrm{kDa}$ His-tagged protein, as shown in Figure 1B. The virus is subsequently amplified to generate sufficient quantities for large-scale (liter volumes) insect cell infection and recombinant protein isolation. The second passage virus (P2) is generated by infecting suspension cultures with an estimated MOI of 0.1 (see protocol). It is vital that the amplification Sf9 suspension culture occupies only a twentieth of the total flask volume. This additional aeration ensures that the resulting virus-containing media, harvested after 3 days $(72 \mathrm{hr})$ post-infection, will generate sufficient quantities of kindlin-3 in the subsequent expression culture. The amplified virus stock (P2) is assumed to possess an expected viral titer of $2 \times 10^{8} \mathrm{pfu} / \mathrm{ml}$ based on a conservative estimate of 100 $\mathrm{pfu} / \mathrm{cell}$ using a cell density of $2 \times 10^{6} \mathrm{cell} / \mathrm{ml}$ during the amplification ${ }^{31}$. Generally, for optimum baculovirus amplification and protein production, the Sf9 cells should be uniform in size and spherical, as shown in Figure 1C. Additionally, viral amplification and protein expression is maximal at $72 \mathrm{hr}$ post-infection, and both are significantly reduced at $96 \mathrm{hr}$ post-infection.

Once virus has been amplified and used to infect Sf9 cells in large scale experiments recombinant kindlin-3 is partially purified by virtue of its engineered $\mathrm{C}$-terminal $\mathrm{His}_{6}$-tag using immobilized metal affinity chromatography, as shown in Figure 2. It is important to carry out the purification at $4{ }^{\circ} \mathrm{C}$ and that sufficient protease inhibitors have been added to prevent proteolysis. The partially-purified kindlin-3 is further purified to near homogeneity by ion exchange chromatography (IEC) using a heparin column, as shown in Figure $\mathbf{3}$. We employed the use of a heparin column instead of a conventional ionic exchange column, as we predicted that the large number of basic residues, including a poly-lysine stretch within the kindlin-3 F1 domain, would interact strongly with the negatively charged sulphate groups of the column. This strategy is particularly useful for DNA- and RNA-binding proteins with basic nucleic acid-binding patches, for example the RNA-binding terminal uridylyltransferase Cid1 ${ }^{32}$. Finally kindlin-3 purity is "polished" by size exclusion chromatography to remove aggregates and achieve homogeneity, as shown in Figure 4. The buffers specified in the protocols are standard buffers frequently used in protein purification for structural analysis. Generally, phosphate-based buffers are avoided for the purification of proteins for structural studies, especially crystallization screening due to the formation of phosphate crystals in the crystallization drops (particularly for experiments at $4^{\circ} \mathrm{C}$ ). However, we performed a Thermofluor-based thermal shift assay to determine which buffers were stabilizing for kindlin-3, as shown in Figure 5. Briefly, a purified protein solution is diluted into buffers that cover a range of $\mathrm{pH}$ and sodium chloride concentrations, therefore forming a 2-dimensional screen. The melting of the protein is measured by observing the fluorescence from Sypro orange dye (molecular probes), that binds to hydrophobic residues within the folded protein core, over the temperature range $20-95^{\circ} \mathrm{C}(293-368 \mathrm{~K})$. The temperature mid-point at which the protein unfolds (transition temperature, $\left.\mathrm{T}_{\mathrm{m}}\right)$ was calculated using the Opticon Monitor software and is described elsewhere ${ }^{33}$. Kindlin-3 was observed to be stable at high sodium chloride concentrations $(500 \mathrm{mM})$ within the $\mathrm{pH}$ range $7.0-9.0$, with a consistent transition temperature $\left(\mathrm{T}_{\mathrm{m}}\right)$ of $55^{\circ} \mathrm{C}$. It was also observed that the $\mathrm{T}_{\mathrm{m}}$ of Kindlin-3 was approximately $55^{\circ} \mathrm{C}$ within the $\mathrm{pH}$ range $7.0-7.5$ irrespective of sodium chloride concentration.

We found that there was limited proteolysis of kindlin-3 during the purification but SDS-PAGE analysis of highly concentrated protein ( 15 mg/ $\mathrm{ml}$ ) demonstrated limited contamination with two additional polypeptides of equal intensity. Oddly, however there is no indication of additional species by size exclusion chromatography, as shown in Figure 4. It is thus thought that the protein is nicked by proteases but remains folded and hydrodynamically indistinguishable from full-length protein. Interestingly, Calpain is a known protease that cleaves kindlin-3 at Tyrosine373, which is in the $\beta 1-\beta 2$ loop of the pleckstrin homology $(\mathrm{PH})$ domain ${ }^{34}$ and may explain our observations. Furthermore, western blotting reveals that one of the polypeptide doublets possesses a C-terminal His-tag and the apparent molecular weight of the doublet, when summed, equals 75 $\mathrm{kDa}$, the same molecular weight as the native protein. The yield of purified recombinant kindlin-3 per liter of Sf9 cells ( $2 \mathrm{~g}$ cell weight) is, at best, $5 \mathrm{mg}$. 
A
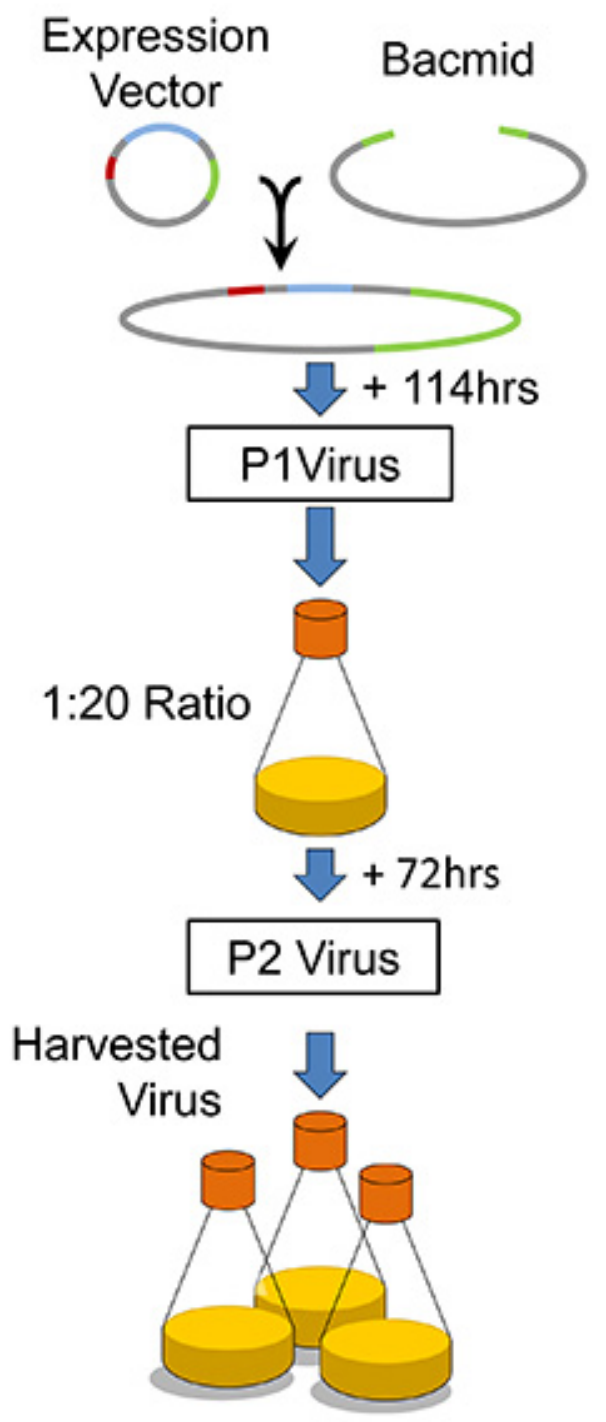

Protein Production
B

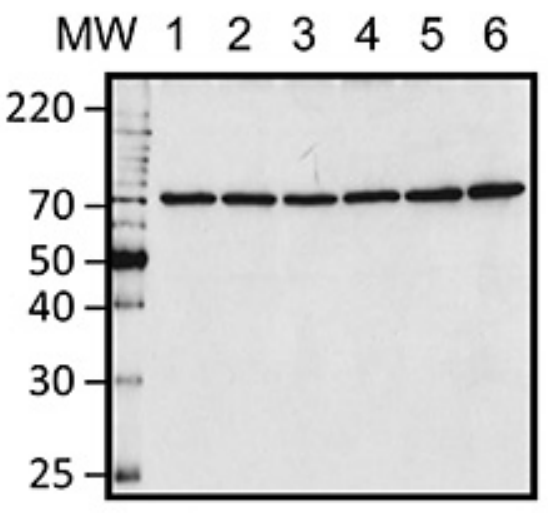

C

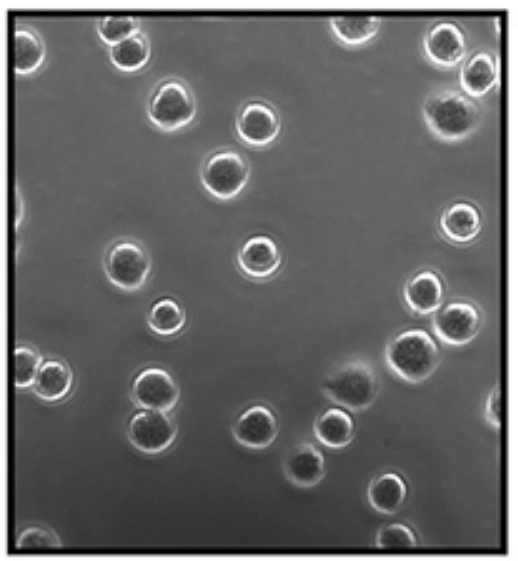

Sf9 cells $(20 X)$

Figure 1. Overview of baculovirus-infected insect cell heterologous protein expression. (A) A schematized overview of baculovirus generation and expression of kindlin-3 in Sf9 cells. In the DNA vector schematics, 5'UTR/ORF603 is colored in red, the ORF1629 is colored in green and, the gene of the protein of interest (P.O.I.) is colored blue. (B) Western blot, using an anti-His ${ }_{6}$ antibody, of six small-scale (2 ml monolayer) cultures (lanes labelled according to culture) of Sf9 cells producing recombinant baculovirus and recombinant murine kindlin-3. (C) Light microscopy image of healthy Sf9 cells grown in suspension in Sf-900 II SFM supplemented with antibiotics and transferred to a 35 mm well tissue culture dish (see protocol). Image is 20X magnification. 


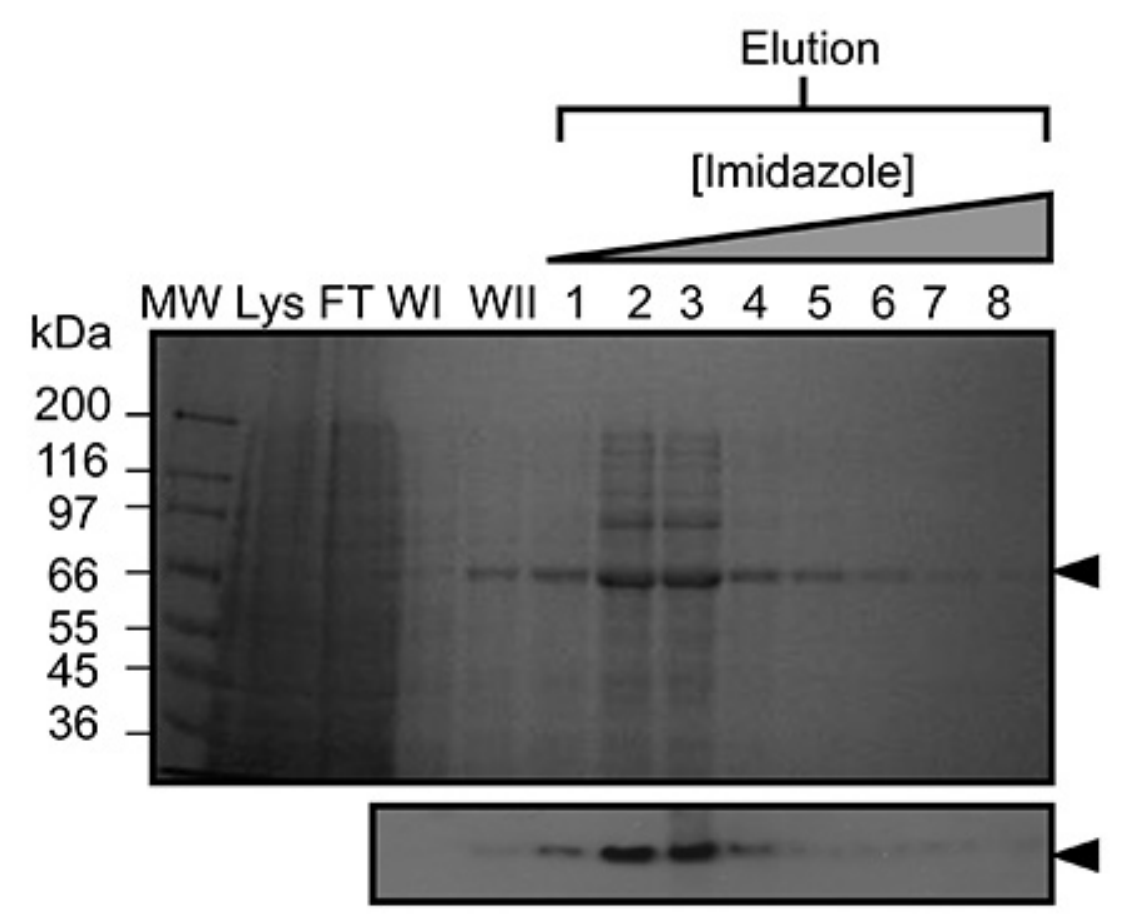

Figure 2. Representative purification of kindlin-3 by immobilized metal affinity chromatography (IMAC). SDS-PAGE of nickel affinity purified recombinant murine kindlin-3 expressed in baculovirus infected Sf9 cells ( $2 \mathrm{~g}$ cell weight). Adsorbed protein was eluted using an imidazole gradient (shown above the gel). Lanes are labelled as follows; MW, molecular weight marker; Lys, whole cell lysate; FT, flow through (unbound); WI, wash 1; WII, wash 2. Western blot analysis (below) was also performed using the elution fractions to confirm the presence of the engineered His-tag on the recombinant protein. Please click here to view a larger version of this figure. 
A

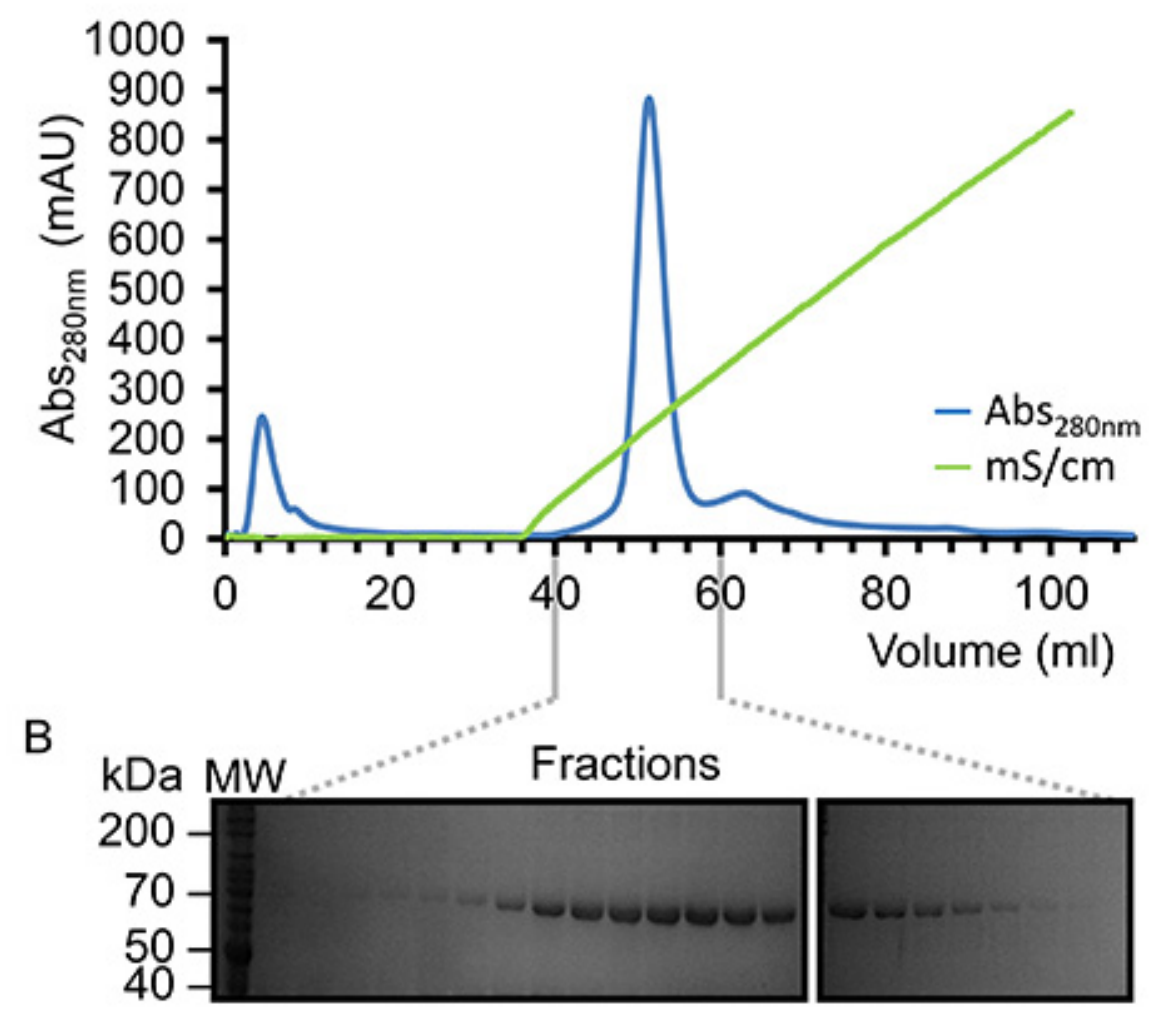

Figure 3. Representative purification of kindlin-3 by Heparin Affinity Chromatography. (A) Elution profile observed at $280 \mathrm{~nm}$ (blue) displaying a single symmetrical peak eluting under a linear sodium chloride gradient (green) using the $\mathrm{NaCl}$ concentration range of $0.05-1.0 \mathrm{M}$. (B) SDS-PAGE analysis of the fractionated elution demonstrating the presence of the $75 \mathrm{kDa}$ protein, kindlin-3 (labeled K3). Please click here to view a larger version of this figure. 
A

B

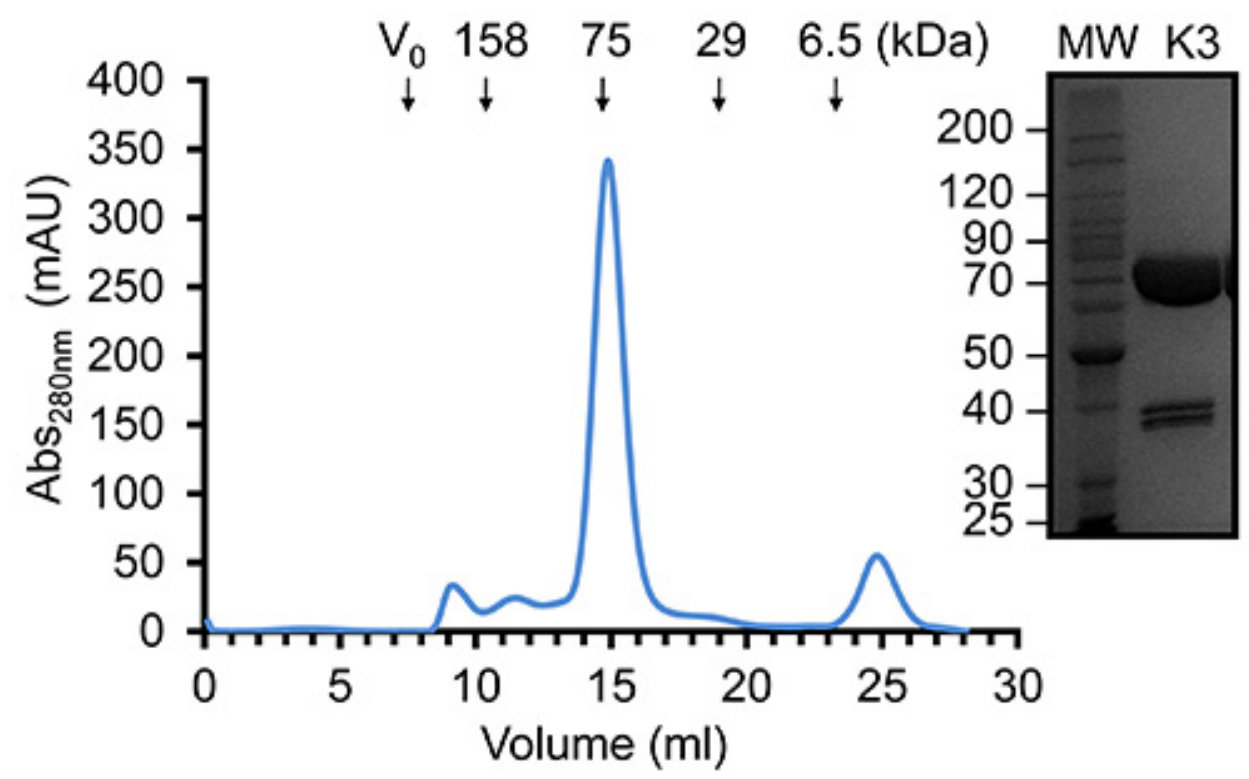

Figure 4. Representative gel filtration chromatography and concentrated kindlin-3. (A) Gel filtration elution profile of purified kindlin-3

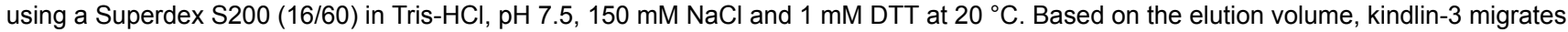
as expected for a $75 \mathrm{kDa}$ protein, suggesting that it is predominantly monomeric. (B) SDS-PAGE of highly concentrated purified recombinant kindlin-3 at $14.5 \mathrm{mg} / \mathrm{ml}$. Please click here to view a larger version of this figure. 

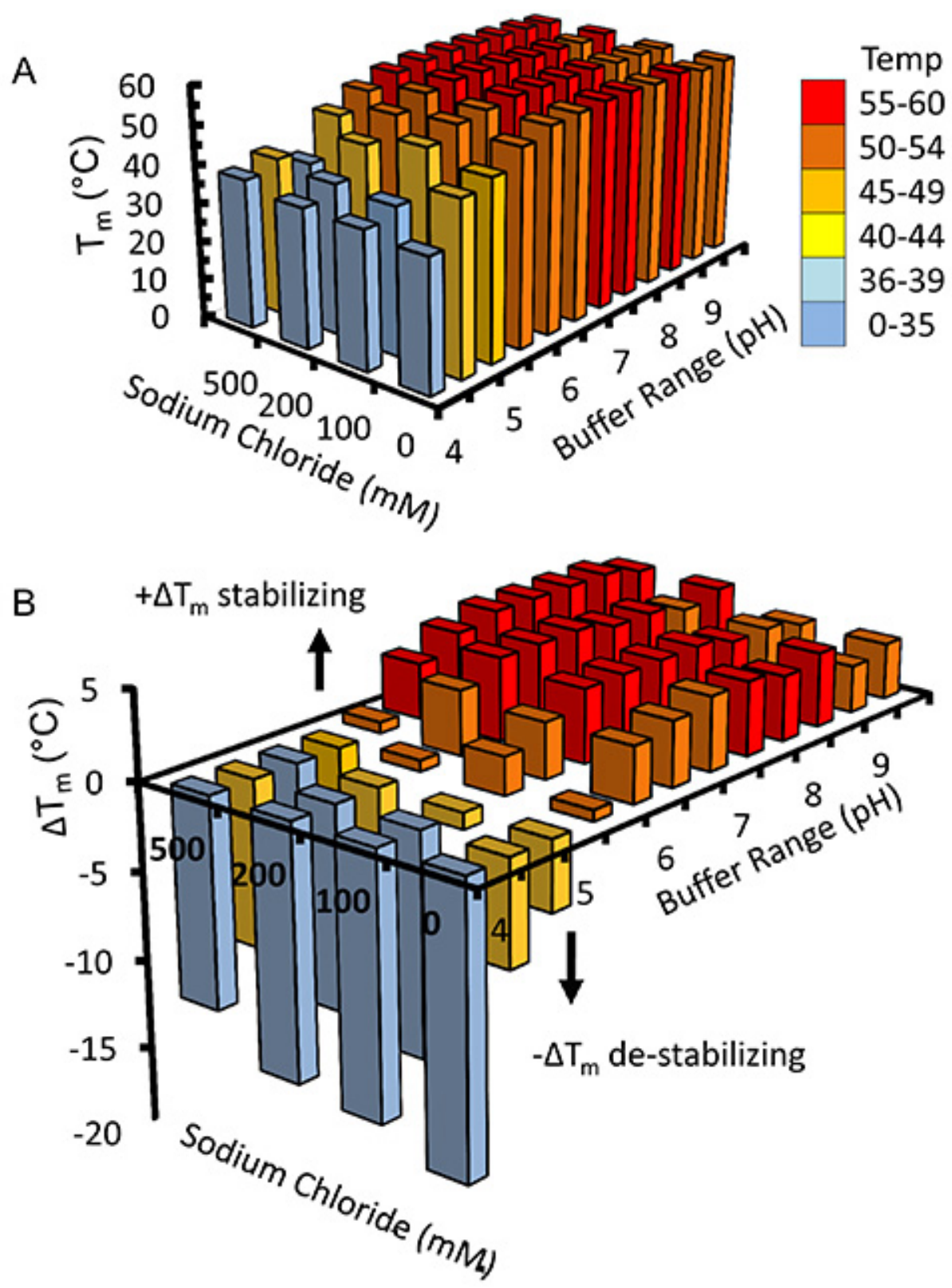

Figure 5. Thermofluor-based Thermal Shift Assay for Buffer Screening. Kindlin-3 was diluted into various buffers comprising a twodimensional screen of $\mathrm{pH}$ versus sodium chloride concentration. Transition temperatures (temperature mid-points) were observed by fluorescence of the hydrophobically bound dye, Sypro orange (molecular probes) and calculated using the Opticon Monitor software. (A) A 3D histogram of the transition temperatures is plotted together with $(B)$ the change in transition temperature from the calculated average of $50.4{ }^{\circ} \mathrm{C}$. For clarity the bars are colored according to the range of temperatures to which they correspond. Please click here to view a larger version of this figure.

\section{Discussion}

Baculovirus expression systems are becoming increasingly popular and an important tool for the production of milligram quantities of recombinant protein for protein characterization using biophysical studies, including X-ray crystallography. Despite being more experimentally demanding the baculovirus expression systems offer several advantages over $E$. coli one of which is a near-native environment for proteins of eukaryotic origin e.g. the presence of appropriate chaperones and opportunity for post-translational modification. In our own efforts to express kindlin-3, alternative expression hosts were used including mammalian cell-lines and bacterial expression strains (unpublished observations). Generally, the many $E$. coli strains tested produced very small quantities of recombinant kindlin-3 ( $\sim .5 \mathrm{mg} / \mathrm{L}$ of culture; unpublished observations). However, the baculovirus-driven expression in insect cells was particularly effective and, in comparison to transient expression in mammalian cells, more amenable to generating the large biomass required for isolating a milligrams of recombinant cytoplasmic proteins (unpublished observations). We speculate that the presence eukaryotic chaperones may allow the efficient production of kindlin-3. 
The baculoviridae infect insect cells and for recombinant protein expression the baculovirus used in this work is based upon the Autographa californica nuclear polyhedrosis virus (AcNPV). In nature the AcNPV, which infects the Autographa californica (alfalfa lopper) insect larvae, requires the polyhedrin protein to form occlusions whereby the virons are encapsulated in a crystalline protein matrix thus providing the necessary protection for their release. In cultured cells the formation of occlusion bodies is not required for replication and is therefore dispensable. In the case of expressing foreign proteins the polyhedrin protein gene can be replaced in a recombinant AcNPV with the gene for the protein of interest. AcNPV can infect other Lepidopteron species and for the purposes of recombinant protein expression army worm Spodoptera frugiperda pupal ovary cells are used. In the approach outlined here, the AcNPV bacmid (BAC10) is engineered so that an essential viral gene, ORF1629, is inactivated by the insertion of chloramphenicol acetyl transferase resulting in a knock-out bacmid (BAC10:KO 1629$)$, such that it is unable to form infectious baculovirions ${ }^{28}$. Cotransfection of Sf9 cells with linearized BAC10:KO 1629 and the FERMT3-containing transfer vector repairs the inactive ORF1629, through transposition, resulting in a viable genome that has also incorporated the FERMT3 gene under the control of the polyhedrin promoter ${ }^{28}$.

We describe a purification protocol for the isolation of highly pure recombinant mouse kindlin-3 via a three step chromatographic approach. The methods used here could easily be applied to other His-tagged proteins. We employed an ion exchange step to further purify kindlin-3 but we believe that this is a further pseudo-affinity step as kindlin-3 possesses a large number of basic residues, including a poly-lysine stretch within its F1 domain. Additionally, kindlin-3 is considered to bind to and interact with the cytoplasmic face of the plasma membrane, where it functions, and therefore we predict that the clustering of basic residues will allow the protein to counter the negatively charged membrane.

The buffers described in the purification protocols are considered standard and are frequently used in structural biology. The thermofluor assay (Figure 5) demonstrates that kindlin-3 is stable in most buffer conditions above pH 6.0. This was particularly useful and important for informing our experiments when studying kinldin-3: $\beta 1_{\mathrm{A}}$ tail interaction by NMR, which yielded excellent spectra at $\mathrm{pH} 6.1$ with low concentrations of $\mathrm{NaCl}{ }^{12}$.

Before any biophysical study can be undertaken, it is important to demonstrate that the purified protein of interest is indeed correctly folded and is functionally active. In a previous publication we demonstrated that the recombinant kindlin-3 expressed and purified using this method was a monomer and monodispersed in solution, as assessed by size-exclusion chromatography, dynamic light scattering, analytical ultracentrifugation and small angle X-ray scattering, and was also capable of binding and recognizing the membrane-distal NPxY and upstream Serine/Threonine cluster of $\beta_{1 \mathrm{~A}}$ cytoplasmic tails ${ }^{14}$, thus confirming that it behaves like the native protein, which is in line with previous cellular and physiological studies ${ }^{14,20,22}$. The use of a thermal stability assay is an additional way of suggesting the proper folding of a protein of interest, as incorrectly folded protein will result in a high fluorescence background due to exposed hydrophobic residues.

The kindlin family of proteins has been the focus of much attention since their unexpected role as essential coactivators of integrins in vivo was discovered. This has triggered much effort to express them recombinantly and resolve their structures. To date limited success has been reported in expressing milligram quantities of full length recombinant protein but we have here described the use of a baculovirus system that permits large scale expression at levels where structural studies become feasible. By generating large quantities of recombinant kindlin-3 we anticipate that this will aid further studies of this protein. The baculovirus-driven method and purification workflow described here for recombinant murine kindlin-3 could also be used to express and purify the other kindlin isoforms, which are also difficult to express and also possess polylysine stretches, and may be further adapted for other cytoplasmic proteins, such as nucleic acid binding proteins, that fail to express in bacterial strains.

\section{Disclosures}

The authors have nothing to disclose.

\section{Acknowledgements}

We thank Weixan Lu for technical assistance in the culture and maintenance of the Sf9 cell stocks. L.A.Y. was supported by a Medical Research Council (MRC) graduate studentship. R.J.C.G was a Royal Society University Research Fellow. The Oxford Division of Structural Biology is part of the Wellcome Trust Centre for Human Genetics, Wellcome Trust Core Award Grant Number 090532/Z/09/Z.

\section{References}

1. Moser, M., Legate, K.R., Zent, R., and Fassler, R. The tail of integrins, talin, and kindlins. Science. 324, 895-899 (2009).

2. $\mathrm{Yu} Y$, et al. Kindlin 2 forms a transcriptional complex with $\beta$-catenin and TCF4 to enhance Wnt signalling. EMBO Rep. 13, 750-758 (2012).

3. Yu Y, et al. Kindlin 2 promotes breast cancer invasion via epigenetic silencing of the microRNA200 gene family. Int $J$ Cancer. doi: $10.1002 /$ ijc.28151 (2013).

4. Meves, A., Stremmel, C., Gottschalk, K., and Fassler, R. The Kindlin protein family: new members to the club of focal adhesion proteins. Trends Cell Biol. 19, 504-513 (2009).

5. Siegel, D.H., et al. Loss of kindlin-1, a human homolog of the Caenorhabditis elegans actin-extracellular-matrix linker protein UNC-112, causes Kindler syndrome. Am. J. Hum. Genet. 73, 174-187 (2003).

6. Hart R., Stanley P., Chakravarty P., Hogg N. The kindlin 3 PH domain has an essential role in integrin LFA-1-mediated B cell adhesion and migration. J. Biol. Chem. doi: 10.1074/jbc.M112.434621 (2013).

7. Liu, J., et al. Structural basis of phosphoinositide binding to Kindlin-2 pleckstrin homology domain in regulating integrin activation. J. Biol. Chem. 286, 43334-43342 (2011).

8. Qu, H., et al. Kindlin-2 regulates podocyte adhesion and fibronectin matrix deposition through interactions with phosphoinositides and integrins. J. Cell Sci. 124, 879-891 (2011).

9. Yates L.A., et al. Structural and Functional Characterisation of the Kindlin-1 Pleckstrin Homology Domain. J. Biol. Chem. 287, 43246-43261 (2012). 
10. Bouaouina $\mathrm{M}$, et al. A conserved lipid-binding loop in the kindlin FERM F1 domain is required for kindlin-mediated allbß3 integrin coactivation. J. Biol. Chem. 287, 6979-6990 (2012).

11. Goult, B.T., et al. The structure of the N-terminus of kindlin-1: a domain important for AlphallbBeta3 integrin activation. J. Mol. Biol. 394, 944-956 (2009).

12. Yates L.A., Fuzery A.K., Bonet R., Campbell I.D., Gilbert R.J. Biophysical Analysis of Kindlin-3 Reveals an Elongated Conformation and Maps Integrin Binding to the Membrane-Distal $\beta$-Subunit NPXY motif. J. Biol. Chem. 287, 37715-37731 (2012).

13. Anthis, N.J., and Campbell, I.D. The tail of integrin activation. Trends Biochem. Sci. 36, 191-198 (2011).

14. Harburger, D.S., Bouaouina, M., and Calderwood, D.A. Kindlin-1 and -2 directly bind the C-terminal region of beta integrin cytoplasmic tails and exert integrin-specific activation effects. J. Biol. Chem. 284, 11485-11497 (2009).

15. Tadokoro, S., et al. Talin binding to integrin beta tails: a final common step in integrin activation. Science. 302, 103-106 (2003).

16. Garcia-Alvarez, et al. Structural determinants of integrin recognition by talin. Mol. Cell. 11, 49-58 (2003).

17. Perera H.D., Ma Y.Q., Yang J., Hirbawi J., Plow E.F., Qin J. Membrane binding of the N-terminal ubiquitin-like domain of kindlin-2 is crucial for its regulation of integrin activation. Structure. 19, 1664-1671 (2011).

18. Ussar, S., Wang, H.V., Linder, S., Fassler, R., and Moser, M. The Kindlins: subcellular localization and expression during murine development. Exp. Cell Res. 312, 3142-3151 (2006).

19. Bialkowska, K., et al. The integrin co-activator Kindlin-3 is expressed and functional in a non-hematopoietic cell, the endothelial cell. J. Biol. Chem. 285, 18640-18649 (2010).

20. Moser, M., Nieswandt, B., Ussar, S., Pozgajova, M., and Fassler, R. Kindlin-3 is essential for integrin activation and platelet aggregation. Nat. Med. 14, 325-330 (2008).

21. Lefort C.T., et al., Distinct roles for talin-1 and kindlin-3 in LFA-1 extension and affinity regulation. Blood. 119, 4275-4282 (2012)

22. Moser M., et al. Kindlin-3 is required for beta2 integrin-mediated leukocyte adhesion to endothelial cells. Nat. Med. 15, 300-305 (2009).

23. Schmidt, S., Nakchbandi, I., Ruppert, R., Kawelke, N., Hess, M.W., Pfaller, K., Jurdic, P., Fassler, R., and Moser, M. Kindlin-3-mediated signaling from multiple integrin classes is required for osteoclast-mediated bone resorption. J. Cell Biol. 192, 883-897 (2011).

24. Malinin N.L., et al. A point mutation in KINDLIN3 ablates activation of three integrin subfamilies in humans. Nat. Med. 15, 313-318 (2009).

25. Svensson, L., et al. Leukocyte adhesion deficiency-III is caused by mutations in KINDLIN3 affecting integrin activation. Nat. Med. 15, 306-312 (2009).

26. Liu Y., Zhu Y., Ye S., Zhang R. Crystal structure of kindlin-2 PH domain reveals a conformational transition for its membrane anchoring and regulation of integrin activation. Protein Cell. 3, 434-440 (2013).

27. Liu J., et al. Structural basis of phosphoinositide binding to kindlin-2 protein pleckstrin homology domain in regulating integrin activation. $J$. Biol. Chem. 286, 43334-43342 (2011).

28. Zhao, Y., Chapman, D.A., and Jones, I.M. Improving baculovirus recombination. Nucleic Acids Res. 31, E6-6 (2003).

29. Berrow, N.S., et al. A versatile ligation-independent cloning method suitable for high-throughput expression screening applications. Nucleic Acids Res. 35, e45 (2007).

30. Nettleship, J.E., Assenberg, R., Diprose, J.M., Rahman-Huq, N., and Owens, R.J. Recent advances in the production of proteins in insect and mammalian cells for structural biology. J Struct. Biol. 172, 55-65 (2010).

31. Wasilko, D.J., et al. The titerless infected-cells preservation and scale-up (TIPS) method for large-scale production of NO-sensitive human soluble guanylate cyclase (sGC) from insect cells infected with recombinant baculovirus. Protein Expr. Purif . 65, 122-132 (2009).

32. Yates L.A., Fleurdépine S., Rissland O.S., De Colibus L., Harlos K., Norbury C.J., Gilbert R.J. Structural Basis for the activity of a cytoplasmic RNA terminal uridylyl transferase. Nat. Struct. Mol. Biol. 19, 782-787 (2012).

33. Sainsbury, S., Ren, J., Saunders, N.J., Stuart, D.I., and Owens, R.J. Crystallization and preliminary X-ray analysis of CrgA, a LysRtype transcriptional regulator from pathogenic Neisseria meningitidis MC58. Acta Crystallogr. Sect. F. Struct. Biol. Cryst. Commun. 64, 797-801 (2008).

34. Zhao, Y., et al. Regulation of cell adhesion and migration by Kindlin-3 cleavage by calpain. J. Biol. Chem. 287, 40012-40020 (2012). 